\title{
RELAÇÃO IDEB E GASTO ALUNO-ANO: ALGUMAS APROXIMAÇÕES DE CORRELAÇÕES E SUA PERTINÊNCIA PARA MELHORIA DOS INVESTIMENTOS EM EDUCAÇÃO
}

\author{
ÍNDICE DE DESARROLLO DE LA EDUCACIÓN BÁSICA Y LA RELACIÓN \\ ESTUDIANTE-AÑO EL GASTO: ALGUNAS APROXIMACIONES DE \\ CORRELACIONES Y SU RELEVANCIA PARA LA MEJORA DE LA INVERSIÓN \\ EN LA EDUCACIÓN
}

\begin{abstract}
RATIO OF EDUCATION DEVELOPMENT INDEX AND EXPENDITURES PER STUDENT-YEAR: SOME APPROXIMATIONS OF CORRELATIONS AND THEIR RELEVANCE TO IMPROVE INVESTMENTS IN EDUCATION
\end{abstract}

\author{
Rejane de OLIVEIRA $^{1}$ \\ Sebastião de Souza LEMES ${ }^{2}$
}

RESUMO: Este estudo apresenta o comportamento do Índice de Desenvolvimento da Educação de duas regiões paulistas correlacionado aos gastos por aluno-ano como proporção do PIB per capita municipal no decorrer dos anos, após a adesão ao Plano de Metas Compromisso Todos pela Educação. O objetivo geral foi analisar e discutir a ocorrência de relação entre os gastos por aluno-ano das séries iniciais do ensino fundamental com o desenvolvimento da qualidade da educação municipal representada pelo indicador de qualidade IDEB como evidência de compromisso e responsabilização com a qualidade da educação. Trata-se de um estudo de caráter quantitativo e foram utilizados métodos estatísticos para análise da relação entre as variáveis. Ficou evidenciada a correlação entre as variáveis IDEB e gasto por aluno-ano como proporção do PIB per capita para os municípios de uma região que não cumpriram suas metas e forte correlação para a segunda região como um todo.

PALAVRAS-CHAVE: IDEB. PDE. Gasto Aluno-ano Qualidade. Plano de Ações Articuladas. Plano de Metas Compromisso Todos pela Educação.

RESUMEN: En este estudio se presenta el comportamiento del Índice de Desarrollo de la Educación dos regiones Paulistas correlacionados con el gasto por alumno-año como proporción del PIB per cápita municipal en los últimos años, después de unirse al objetivo del plan Todo por Compromiso Educación. El objetivo general fue analizar y discutir la relación entre la ocurrencia del gasto por alumno-año de la serie inicial de educación básica con el desarrollo de la calidad de la educación municipal representada por el indicador de calidad de IDEB como prueba del compromiso y la responsabilidad de la calidad de la educación. Se trata de un estudio cuantitativo de carácter y los métodos estadísticos utilizados para el análisis de la relación entre las

\footnotetext{
${ }^{1}$ Doutoranda em Educação Escolar. UNESP -Universidade Estadual Paulista. Faculdade de Ciências e Letras. Pós-graduação em Educação. E-mail: rejane571 @ hotmail.com

${ }^{2}$ Docente. UNESP -Universidade Estadual Paulista. Faculdade de Ciências e Letras-Departamento de Ciências da Educação: E-mail: ss.lemes2@gmail.com
} 
variables. Existe una correlación evidente entre las variables IDEB y el gasto por alumno-año como proporción del PIB per cápita de los municipios de una región que no cumplió con sus objetivos y fuerte correlación con la segunda región en su conjunto.

PALABRAS CLAVE: IDEB. PDE. La calidad del gasto estudiante años. Las acciones del plan de relación. Plan de Metas Compromiso Todos por la Educación.

ABSTRACT: This study presents the behavior of the Education Development Index in two regions in São Paulo State, correlated with the spending per student a year as a proportion of the municipal GDP per capita during the years, after joining the Target Plan Everyone for Education Commitment. The general aim was to analyze and discuss the relation between spending per student a year in the initial grades of basic education and the development of the municipal education quality represented by EDIB quality indicator as evidence of commitment and responsibility to the quality of education. This is a quantitative study, which used statistical methods for analysis of the variables. There is an evident correlation between the EDIB variables and spending per student a year, as a proportion of GDP per capita for municipalities in a region that has not accomplished their goals, and there is also a strong correlation to the second region as a whole.

KEYWORDS: EDIB. EDP. Student a Year Spending Quality. Articulated Action Plan. Target Plan Everyone for Education Commitment.

\section{Introdução}

As políticas educacionais implantadas nos últimos 15 anos mudaram significativamente o cenário da educação com a aprovação do Plano Nacional de Educação (2001-2011) e tende a avançar com a aprovação do novo PNE. Políticas e programas foram criados pelo Ministério da Educação para consecução das estratégias definidas no plano, com objetivo de atingir as metas. A principal política educacional criada após o primeiro PNE foi o Plano de Desenvolvimento da Educação - PDE e derivado dele o Plano de Metas Compromisso Todos pela Educação.

O objetivo central do PDE foi criar um sistema de articulação entres os entes federados, e para tanto, criou-se o plano de ações articuladas - PAR, como elo entre as esferas governamentais. Essa articulação é feita mediante adesão de cada município e visa à implementação de 28 diretrizes para educação com foco no comportamento progressivo do Índice de Desenvolvimento da Educação Básica - IDEB no decorrer dos anos, de forma, a atingir a nota 6,0 até o ano de 2021 com a finalidade de diminuir as desigualdades educacionais existentes no Brasil. (BRASIL.2007). 
O objetivo de alcançar índices numéricos representando qualidade em todas as etapas da educação básica se mantém no Plano Nacional da Educação (2014-2024). O plano possui 20 metas e 254 estratégias, a meta com o maior número de estratégias, é a meta 7, com trinta e seis estratégias, essa meta diz respeito à qualidade da educação básica representada pelo IDEB. Esse plano, diferente do anterior, prevê ampliação de recursos financeiros a serem destinados à educação para os próximos 10 anos para alcançar as metas previstas (BRASIL. 2014).

Dessa forma, a questão que motiva este estudo é: os gastos por aluno-ano, realizado por municípios, após a adesão ao Plano de Metas Compromisso Todos pela Educação se correlaciona à evolução do IDEB como forma de comprometimento e responsabilidade com a educação?

A partir de análise estatística de correlação e modelo de regressão tomamos o IDEB como variável dependente e o gasto por aluno-ano em relação ao PIB per capita municipal como variável independente. Buscamos identificar uma aproximação no estabelecimento dessa relação. É importante mencionar que o cálculo de Correlação não estabelece relação de causa e efeito, apenas dá evidências se as variáveis estão correlacionadas (LARSON, 2010).

A análise dos dados considerou a condição financeira de 38 municípios paulistas da região de Barretos e região Central através de seus $\mathrm{PIBs}^{3}$ per capita, de forma a estabelecer a proporção do gasto por aluno-ano/PIB per capita, como também considerou a projeção do IDEB de 2009 a 2013 de cada município e o cumprimento dessas metas no ensino fundamental dos anos iniciais.

Discutir esse tema requer compreensão dos aspectos políticos e financeiros, visto que, influenciam diretamente a consecução das ações para implantação e implementação de políticas educacionais em busca de melhoria da qualidade da educação. Assim, considerou-se neste trabalho o estudo do custo de uma educação de qualidade e previsão orçamentária para realização dos investimentos em educação.

\section{$O$ custo de uma educação de qualidade}

${ }^{3}$ O PIB per capita é a soma da renda de todas as atividades econômicas acrescidas dos impostos sobre os produtos consumidos, pode ser entendido também como a soma das rendas primárias. 
A Constituição Federal prevê, em seu Artigo 206, que à Educação será garantido Padrão de Qualidade e a Lei de Diretrizes e Bases cita que a educação contará com,

padrões mínimos de qualidade de ensino, definidos como a variedade e quantidade mínimas, por aluno, de insumos indispensáveis ao desenvolvimento do processo de ensino-aprendizagem. (BRASIL, Lei 9494/96, Art. $3^{\circ}$, Inciso IX)

O principal financiador da educação básica hoje é o Fundo de Manutenção e Desenvolvimento da Educação Básica e de Valorização dos Profissionais da Educação FUNDEB. O fundo é composto por $20 \%$ dos impostos arrecadados pelas esferas governamentais, a emenda constitucional n. 53/2006 foi a que criou o FUNDEB e, posteriormente, foi regulamentado pela Lei n. 11.494/2007 e pelo Decreto $n$. 6.253/2007. Trata-se de um fundo especial, de âmbito estadual, ou seja, cada estado da federação possui um fundo, totalizando vinte e sete fundos. A União tem a incumbência de complementar esse fundo quando no âmbito dos estados o valor por aluno não alcançar o mínimo definido nacionalmente, a vigência do fundo está prevista para até o ano de 2020 (CALLEGARI, 2009).

O critério de distribuição leva em conta o número de alunos matriculados em cada esfera de governo, de acordo com a atuação prioritária, ou seja, municípios recebem os recursos baseado no número de alunos da educação infantil e do ensino fundamental, e os estados, no número de alunos do ensino fundamental e médio. (BRASIL, 1989, Art. 211, $\S \S 2^{\circ}$ e $3^{\circ}$ ). Utiliza-se, também, critério de ponderação que varia de acordo com os desdobramentos da Educação Básica deliberados anualmente pela Comissão Intergovernamental de Financiamento para a Educação Básica de Qualidade.

O número de alunos é informado pelo Censo Escolar, publicado no Diário Oficial da União ao final do segundo semestre de cada ano. Caso haja divergência entre o número verificado pelo município com o número publicado e divulgado pelo Ministério da Educação e Cultura e Instituto Nacional de Estudos e Pesquisas - INEP, cabe a cada Conselho de Acompanhamento e Controle Social - CACS - solicitar aos Chefes do Poder Executivo que entrem com recurso junto ao Ministério da Educação para que corrija o número de matrículas.

Quando o valor médio ponderado por aluno não alcançar o mínimo definido nacionalmente, a União complementa o FUNDEB, essa complementação se refere ao âmbito Estadual. O piso nacional anual por aluno para o exercício de 2014 foi de $\mathrm{R} \$$ 2.022,51, estimados no ano de 2013, conforme Portaria Interministerial n. 16/2013. Dez 
Estados são beneficiados por essa complementação, são eles: Alagoas, Amazonas, Bahia, Ceará, Maranhão, Pará, Paraíba, Pernambuco, Piauí e Rio Grande do Norte.

Os municípios paulistas contaram com o repasse de $\mathrm{R} \$ 3.390,50$ por aluno para os anos iniciais urbanas do Ensino Fundamental, conforme Portaria Interministerial n. 08/15, referente ao exercício de 2016. Esse valor significa em média $29 \%$ a mais do que a média nacional, $\mathrm{R} \$ 2.627,00$. Podemos perceber que o Estado de São Paulo não necessita de complemento da União para constituição do FUNDEB ${ }^{4}$ (BRASIL, 2013a).

Para completar os $25 \%$ obrigatórios constitucionalmente, os municípios devem aplicar os 5\% de recursos próprios de suas receitas de impostos, mais os $20 \%$ previstos referentes ao FUNDEB. Isso significa que há uma variação no gasto por aluno-ano devido à capacidade físcal de cada município. Assim como há uma variação no desenvolvimento do índice de qualidade da educação representada pelo IDEB para cada município. Dessa forma, os gastos por aluno-ano parece não ser suficiente para garantir o padrão de qualidade da educação em todo o território nacional. Mas essa realidade se aplica aos municípios paulistas?

O Custo Aluno Qualidade Inicial - CAQi, apresentado pela Campanha Nacional pelo Direito à Educação como uma referência para definir a quantidade de insumos mínimos para oferta de educação de qualidade a todos os alunos, foi relatado no Parecer 008/10 do Conselho Nacional de Educação - CNE e concluiu-se que, para construir um país igualitário e com justiça social, é necessário que haja no sistema nacional de educação equidade e qualidade (BRASIL, 2010).

Segundo Lemes (2013), as injustiças sociais produzidas e reproduzidas no âmbito escolar ocorrem a partir da negação dos direitos de: desenvolvimento pessoal, social e político do sujeito. $\mathrm{O}$ desenvolvimento pessoal contribui com o desenvolvimento da autonomia do indivíduo, o social diz respeito ao direito à inclusão, e o desenvolvimento político contribui para a participação do sujeito nas transformações da ordem social. Nesse sentido, a negação desses direitos contradiz o princípio da democratização da escola que se queira de qualidade.

Trata-se, portanto, de um desafio nacional a ser vencido e que depende do compromisso e responsabilidade de todos os entes federativos, pois a qualidade social

\footnotetext{
${ }^{4}$ Receitas que compõe o FUNDEB: Fundos de Participação dos Estados e dos Municípios (FPE e FPM), Imposto sobre Produtos Industrializados e exportados (IPI exportação), Imposto sobre Circulação de Mercadorias e Prestação de Serviços (ICMS), Imposto sobre Transmissão Causa Mortis e Doações (ITCMD), Imposto sobre Propriedade de Veículos Automotores (IPVA), quota parte de 50\% do Imposto Territorial Rural devida aos Municípios (ITR).
} 
da educação, segundo o Parecer 008/10 do Conselho Nacional da Educação, significa acesso, permanência, aprendizagem e conclusão da Educação Básica (BRASIL. 2010)

Nesse sentido, o CAQi estabelece, com base na legislação vigente, os padrões mínimos de qualidade para Educação Básica por etapas e suas fases, pela modalidade de escola e pressupõe o aumento progressivo dos seus valores. O valor do CAQi considerou os insumos essenciais ao desenvolvimento dos processos ensino aprendizagem, sendo o IDEB o indicador de aferição dessa qualidade quando atingir a nota 6,0, essa nota está prevista para ser alcançada até o ano de 2021. Para o cálculo do CAQi, foi considerado o tamanho da escola, a jornada dos alunos, a relação professor/aluno e a valorização dos profissionais do magistério.

No entanto, o Custo Aluno Qualidade Inicial ainda não foi implantado, está previsto na meta 20 e estratégia 20.7 do Plano Nacional de Educação a ser criado até 2016 conforme prevê a Lei n. 13.005/14.

A título de comparação para o objeto do nosso estudo, o valor calculado em 2008, pela Campanha, para custear a educação do ensino fundamental dos anos iniciais, era de $\mathrm{R} \$ 2.194,00$, sendo $51 \%$ a mais do que o valor aluno estipulado pelo FUNDEB daquele ano.

Se corrigirmos os valores do FUNDEB do Estado de São Paulo, ano 2015, em que o custo aluno é de $\mathrm{R} \$ 3.390,50$, colocando $51 \%$ a mais, o custo aluno qualidade inicial hoje seria de $\mathrm{R} \$ 5.118,00$. Ou seja, seriam necessários $\mathrm{R} \$ 5.118,00$, por alunoano para garantir o pagamento dos professores, estrutura física e de materiais pedagógicos para oferta de ensino, dos anos iniciais, com qualidade.

Este estudo aponta variação no valor gasto por aluno-ano para garantir a manutenção e desenvolvimento do ensino - MDE, de cada município estudado, devido à capacidade fiscal dos municípios, visto que, além dos 20\% do FUNDEB o município é obrigado a investir 5\% da sua receita própria de impostos para cumprir o dispositivo legal de aplicar 25\% das receitas de impostos em educação.

\section{Manutenção e Desenvolvimento do Ensino - MDE}

A Constituição Federal, em seu artigo 212, e a Lei de Diretrizes e Bases da Educação Nacional - LDB -, em seu artigo 70, tipificam a referida manutenção e desenvolvimento do ensino. As despesas próprias da Educação se relacionam a salário e 
encargos do professor, dos especialistas, do treinamento do profissional do magistério, dos servidores que atuam na escola. Diz respeito também à construção, conservação e manutenção de creches e escolas, levantamentos estatísticos, estudos e pesquisas relativas ao aprimoramento da qualidade do ensino e à sua expansão, aquisição de materiais necessários às atividades escolares, bolsas de estudo a alunos de escolas públicas e privadas, transporte de alunos, o que inclui compra de veículos para a locomoção do alunado, bem como a manutenção desses veículos (BRASIL, 2012, p.32).

As despesas consideradas impróprias estão definidas no artigo 71 da LDB referem-se a pesquisas não vinculadas às instituições de ensino ou que não visem aprimorar a qualidade do ensino ou sua expansão, a subvenção a instituições assistenciais, formações que não compreendam os profissionais da educação, merenda escolar, programas escolares de assistência médico-odontológica, farmacêutica, psicológica e social, obras de infraestrutura que beneficiam creches e escolas, porém externas ao prédio, pagamento dos profissionais da educação em desvio de função ou em atividade alheia ao ensino; qualquer despesa alheia ao ensino fundamental (BRASIL, 2012, p.32).

Para o Tribunal de Contas do Estado de São Paulo, órgão responsável pela fiscalização e controle dos gastos públicos, os principais motivos para negação das contas de prefeitos são gastos considerados estranhos ao que dispõe a lei. São exemplos: despesas com pessoal em desvio de função; despesas com alimentação infantil e uniforme escolar; insumos e equipamento utilizados na merenda escolar; despesas com pessoal da merenda; escola terceirizada; construção de bibliotecas, museus e ginásios esportivos; aquisições globais de bens e serviços que servem a vários outros setores da Administração (como combustíveis, material de escritório ou de limpeza, peças de reposição de frota escolar, aquisição de veículos escolares sem as condições exigidas no Código Brasileiro de Trânsito, vale-refeição, cesta-básica, vale-transporte, nos $60 \%$ do FUNDEB destinados aos profissionais do magistério, entre outras) (TCE, 2012).

Portanto, o MDE deve ser investido, exclusivamente, em ações que visam à qualidade do ensino público e o seu aprimoramento a partir de planejamento do orçamento para educação.

\section{Previsão orçamentária para concretização das metas previstas}


A adesão ao Plano de Metas Compromisso Todos pela Educação prevê a elaboração do Plano de Ações Articuladas que se inicia com o diagnóstico da realidade educacional local nas quatro dimensões que compõem a sua estrutura. Dimensão 1 Gestão Educacional; Dimensão 2 - Formação de Professores e de Profissionais de Serviço e Apoio Escolar; Dimensão 3 - Práticas Pedagógicas e Avaliação; Dimensão 4 - Infraestrutura Física e Recursos Pedagógicos.

A elaboração do plano passa por três etapas: diagnóstico da situação educacional local; plano de trabalho e fase de análise técnica. Uma vez concluído, o documento, com seus resultados, é enviado eletronicamente aos técnicos do Fundo Nacional de Desenvolvimento da Educação - FNDE - e MEC. Sendo aprovado, o ente é beneficiado com transferência direta de recursos às contas específicas para realização das ações previstas no plano (BRASIL, 2013a p.85).

A metodologia adotada pelo MEC para ajudar financeiramente os entes federados segue uma lógica de pontuação condicionada à responsabilidade da união ou do município. Ou seja, parte da demanda diagnosticada será analisada pelo Ministério da Educação, para auxílio financeiro, e outra parte corresponde ao município, que se compromete, por assinatura de termo de cooperação técnica, a realizar as melhorias necessárias.

Dessa forma, os planos de cada governo devem prever os gastos com educação para execução das ações previstas no plano de ações articuladas, compreendendo todas as dimensões do plano.

$\mathrm{O}$ ordenamento jurídico que dá forma e disciplina ao planejamento governamental de qualquer ente federativo é a Constituição Federal de 1988, a qual prevê que as "leis de iniciativa do Poder Executivo estabelecerão: o plano plurianual (PPA); as diretrizes orçamentárias (LDO); os orçamentos anuais (LOA)” (BRASIL, 1989).

Dessa forma, o plano plurianual estabelecerá as diretrizes, objetivos e metas da administração pública; a lei de diretrizes orçamentárias estabelecerá as metas e prioridades da administração; a lei orçamentária anual fará os ajustes quanto às alterações na legislação e os critérios de aplicação dos recursos financeiros. $O$ pressuposto para o planejamento governamental funcionar dessa forma é a garantia de uma gestão fiscal responsável, impulsionando o gestor público a planejar suas ações com objetivos de aumentar a eficiência da ação governamental e alcançar resultados. 
Ressalte-se que o PPA, a LDO e a LOA são instrumentos fundamentais para a gestão dos recursos públicos das três esferas do poder executivo, Federal, Estadual e Municipal, mediante o processo de Planejamento do Orçamento (BRASIL, 1989).

Considerando que o governo federal, desde a proclamação da república, vem tentando instituir ações que garantam o desenvolvimento econômico do país, é evidente que possui planos bem elaborados pelos técnicos do Planejamento e Orçamento, dos quais podemos citar seis Planos Plurianuais, elaborados após a constituição de 88: os planos de 1991-1995; 2000-2003 - Plano Avança Brasil; 2004-2007 - Plano Brasil um País de Todos; 2008-2011 - Plano Desenvolvimento com Inclusão Social e Educação de Qualidade; 2012-2015 - Plano Mais Brasil (MELO, 2013).

Esses planos têm influências diretas no desenvolvimento da educação nacional e nas políticas públicas educacionais. O principal documento que traduz a intenção do governo federal para com a educação é o Plano Nacional de Educação - PNE, cujo conteúdo deve estar previsto nos planos plurianuais para o setor da educação. Assim como os planos de educação estaduais e municipais devem constar nos planos plurianuais desses governos para sua concretização, em consonância com o Plano Nacional de Educação.

Nesse sentido, o PNE é um instrumento de planejamento educacional para todos os níveis de governo com metas, prioridades, diretrizes e estratégias de ação com objetivos definidos a serem cumpridos em dez anos. O PNE está previsto no artigo 214 da CF/88 e modificado pelas Emendas Constitucionais n. 53, de 2006, e n ${ }^{\circ}$ 59, de 2009. A redação dada ao PNE é a seguinte:

Art. 214. A lei estabelecerá o plano nacional de educação, de duração decenal, com o objetivo de articular o sistema nacional de educação em regime de colaboração e definir diretrizes, objetivos, metas e estratégias de implementação para assegurar a manutenção e desenvolvimento do ensino em seus diversos níveis, etapas e modalidades por meio de ações integradas dos poderes públicos das diferentes esferas federativas que conduzam a: (Redação dada pela Emenda Constitucional n. 59, de 2009) I - erradicação do analfabetismo; II - universalização do atendimento escolar; III melhoria da qualidade do ensino; IV - formação para o trabalho; V promoção humanística, científica e tecnológica do País. VI estabelecimento de meta de aplicação de recursos públicos em educação como proporção do produto interno bruto. (Incluído pela Emenda Constitucional n. 59, de 2009).

A CF/1988 prevê a obrigatoriedade de um plano nacional de educação, porém sua regulamentação ocorreu a partir da Lei de Diretrizes e Bases da Educação Nacional 
de 1996 e conforme a Declaração Mundial sobre Educação para Todos. A LDB de 1996 estipulou prazo para o encaminhamento do PNE, fazendo com que a sociedade civil e entidades da área educacional se organizassem e elaborassem uma proposta de plano, no entanto, foi ignorado na época, por Fernando Henrique Cardoso, pois o PNE aprovado manteve a proposta do executivo,

Com os mesmos onze temas, com três subitens para cada tema: Diagnóstico, Diretrizes, Objetivos e Metas. Suas diretrizes e metas estavam em sintonia com a Declaração Mundial de Educação. As metas totalizaram 295, resultantes da fusão e ou incorporação das metas das propostas do executivo (248) e da sociedade (118) e de emendas. Este elevado número de metas acabou por dificultar o foco em questões primordiais, uma vez que estas não eram mensuráveis e não apresentavam, por exemplo, punições para aqueles que não cumprissem o que foi determinado. (MELO, 2013, p.86)

A Lei n. 10.172/2001 instituiu o Plano Nacional de Educação para vigorar no período 2001-2010 e teve nove metas vedadas por envolver questões financeiras por indicação da área econômica do governo. Esse veto impossibilitou que todas as metas que visavam avanços qualitativos e quantitativos na educação nacional se efetivassem como política de Estado, e sim como política de governo (DOURADO et al. 2011, p.14).

Vale mencionar que, no que se refere à compatibilização dos Planos Plurianuais vigentes no período de 1997 a 2010, segundo Melo (2013, p.89), “Todos os Planos Plurianuais dessa época, 2000-2003, 2004-2007 e 2008-2011 foram elaborados e aprovados sem considerar as metas constantes do PNE 2001-2010".

Isso demonstra, associando-se ao desinteresse político na efetivação e consolidação do Plano e à ausência da regulamentação do regime de colaboração entre os entes federados, a perda de credibilidade, ocasionando o fraco desempenho deste Plano.

Em 2010, o Ministério da Educação enviou ao Congresso a proposta de um novo plano para a vigência de 2011-2021. O novo plano foi aprovado recentemente com vigência de 2014-2024 e determina o investimento de 10\% do Produto Interno Bruto PIB -, sendo 7\% em três anos após a aprovação da lei e o restante até o fím da vigência do Plano. A proposta resultou dos debates e sugestões realizados na CONAE, Conferência Nacional de Educação, realizada em abril de 2010. A Conferência teve como tema central "Construindo o Sistema Nacional Articulado de Educação: O Plano Nacional de Educação, Diretrizes e Estratégias de Ação”. É possível perceber um 
avanço na elaboração do PNE a partir da CONAE, pois se constitui no produto da participação de 3,5 milhões de participantes, com 450 mil delegados representando as conferências municipais, intermunicipais, estadual e nacional (OLIVEIRA; DOURADO et al, 2011).

Dessa forma, o PNE serve como "referência plurianual e base estratégica para políticas públicas da educação nacional nas três esferas de governo por um período de 10 anos" (MELO, 2013, p. 93).

Nesse sentido, o PNE, por um lado, se configura como:

Conjunto de intenções e ações com os quais os Poderes Públicos respondem às demandas de escolarização da população e por outro é um exercício de previsão de estratégias e ações do Estado, com gastos públicos, para responder aos direitos de todos (MELO, 2013, p.93).

Em relação à previsão orçamentária para concretização do Plano Nacional de Educação, vale destacar que, pela primeira vez, o PPA 2012-2015 foi elaborado em consonância com os compromissos e metas estabelecidos de acordo com as ações estratégicas previstas no Plano de Desenvolvimento da Educação, elaborado para atingir as metas do PNE 2001-2010.

O Plano Nacional da Educação aprovado, Lei n. 13.005/14, estabelece 20 metas e 254 estratégias para o desenvolvimento da educação em todo o país, e prevê que todos os estados e municípios aprovem seus planos até junho de 2015. No entanto, a concretização e o cumprimento das metas e estratégias vão depender da mobilização conjunta de forma articulada entre os governos.

Somente assim, o pacto federativo e o regime de colaboração e cooperação entre os entes federados, preconizado pela CF de 1988, garantirão que ele seja expressão de políticas de Estado (OLIVEIRA; DOURADO et al. 2011).

É nesse sentido que o regime de colaboração torna-se fator determinante para o sucesso das ações em educação, pois o governo federal não irá atingir as metas do PNE sozinho. A adesão dos estados, municípios e sociedade civil é de grande importância para a efetivação desse plano. A consciência dessa participação se concretiza com o Compromisso Todos pela Educação, o Plano de Ações Articuladas e os planos municipais de educação, onde cada ente federativo se compromete a investir em educação, mediante previsão orçamentária dos gastos com educação, visando à qualidade da educação.

Nesse sentido, apresentamos, a seguir, a média dos valores gastos por aluno-ano em relação ao PIB per capita municipal, como evidência de compromisso e 
responsabilização pela qualidade da educação de duas regiões do Estado de São Paulo, relacionando-a com o desenvolvimento do IDEB local.

\section{Resultados da relação IDEB e a proporção dos gastos aluno-ano em relação ao PIB-percapita nos municípios analisados das regiões de Barretos e região Central}

O gasto aluno-ano em relação ao PIB per capita dos municípios é um dos indicadores que permite perceber a prioridade dada à educação, uma vez que o PIB representa o nível de riqueza de um determinado município. O gasto mínimo por alunoano está previamente definido para todos os municípios e refere-se ao FUNDEB, somado à complementação do próprio município para aplicação integral de $25 \%$ da receita vinculada à Educação para atender as necessidades básicas de oferta da educação de qualidade.

Segundo o que dispõe o decreto n. 6.094/07, o Índice de Desenvolvimento da Educação - IDEB é o indicador da qualidade da educação, adotado atualmente pelo Ministério da Educação, como forma de verificar o cumprimento dessas metas.

Assim, verificamos a relação IDEB x Gastos aluno-ano/PIB per capita dos municípios das regiões de Barretos e Central, com objetivo de identificar evidência de responsabilidade e compromisso com a qualidade da educação representada pela evolução do IDEB.

A variável dependente IDEB é iniciada com a nota de 2005 (5,2), mas o cálculo é iniciado em 2007.

Considerando o total dos municípios analisados da região de Barretos, o PIB per capita médio da região é de $\mathrm{R} \$ 22.662,00$, a média de gasto por aluno-ano, em 2013, foi de $\mathrm{R}$ \$ 6. 929,00, o IDEB médio dessa região, é de 5.7. O cálculo da correlação é negativo e explica em $25 \%$ essa relação, de acordo com o teste estatístico a relação é sem significância.

$\mathrm{Na}$ região Central de todos os municípios analisados, a relação PIB per capita e média de gastos por aluno apresenta outro resultado, o PIB per capita médio é de R\$ 21.687,00 e a média de gasto por aluno-ano é de R\$ 6.393,00, o IDEB médio é de 5.9, o cálculo da correlação é positiva e explica em $92 \%$ a relação, é considerada uma relação significativa. 
Comparando as duas regiões tem-se uma contradição ao relacionar às mesmas variáveis, considerando todos os municípios analisados, mas quando separamos os municípios que alcançaram as metas obtemos resultados significativos.

Dentre os municípios analisados que estão com IDEB acima ou igual à meta na região de Barretos, a média dos gastos por aluno dos municípios que cumprem suas metas é de $\mathrm{R} \$ 6.688,00$ por aluno-ano, em 2013, e PIB per capita médio de R\$ 20.363,00, com IDEB de 6,1, a relação, nesse caso, mostra uma tendência positiva para o IDEB e explica a correlação em $39 \%$.

Nos municípios da região Central que cumpriram suas metas o determinante de correlação é de $84 \%$, a média do IDEB é de 6,4 , com gastos por aluno no valor de R\$ 6.731,00. O PIB per capita médio desse grupo é de R \$23.473,00.

Podemos perceber que nas duas regiões analisadas ao agrupar os municípios que cumpriram suas metas e calcular a relação IDEB e gasto por aluno-ano há uma forte correlação positiva.

Quando isolamos os municípios da região de Barretos que não cumpriram a meta do IDEB e relacionamos as variáveis verifica-se uma correlação moderada e negativa, explicando em $61 \%$ a relação entre as variáveis. Esse comportamento ocorre devido à oscilação entre uma variável e outra, o IDEB não avança, ora sobe, ora cai, assim como os gastos que se mantêm quase estáveis durante os anos analisados. No ano de 2013 o gasto médio desses municípios foi de $\mathrm{R} \$$ 7.307,00 e o PIB per capita médio é de $\mathrm{R} \$ 26.264,00$ e IDEB médio de 5,2.

A relação IDEB x gasto aluno-ano dos municípios da região Central que não cumpriram suas metas estabelece uma correlação forte que explica em $98 \%$ a relação entre as variáveis. A média do IDEB dos municípios desse grupo é de 5,4 e gasto médio de $\mathrm{R} \$ 5.886,00$, a média do PIB per capita é de $\mathrm{R} \$ 18$. 679,00.

As regiões de Barretos e Central possuem PIB per capita semelhantes, porém a região de Barretos gasta mais por aluno-ano em relação ao seu PIB per capita do que a região Central e tem apresentado incoerências, pois à medida que aumenta o gasto aluno-ano, diminui o IDEB, sendo que a proposta é aumentar o IDEB progressivamente, a partir de políticas locais de organização e estruturação do processo educativo, visando a qualidade da educação. A região Central gasta menos por aluno-ano em relação ao seu PIB per capita, mas tem demonstrado evolução no IDEB no decorrer dos anos, com indicador de qualidade acima da média, comparado à região de Barretos. É importante 
mencionar que o cálculo de correlação não resulta em causa e efeito, somente explica que há relação entre as variáveis.

As regiões de Barretos e Central possuem PIB per capita semelhantes, porém a região de Barretos gasta mais por aluno-ano em relação ao seu PIB per capita do que a região Central e tem apresentado incoerências, pois à medida que aumenta o gasto aluno-ano, diminui o IDEB, sendo que a proposta é aumentar o IDEB progressivamente, a partir de políticas locais de organização e estruturação do processo educativo, visando a qualidade da educação. A região Central gasta menos por aluno-ano em relação ao seu PIB per capita, mas tem demonstrado evolução no IDEB no decorrer dos anos, com indicador de qualidade acima da média, comparado à região de Barretos. É importante mencionar que o cálculo de correlação não resulta em causa e efeito, somente explica se há relação entre as variáveis.

\section{Considerações finais}

As justificativas para a baixa qualidade da educação, de uma maneira geral, são as de que os recursos financeiros não são suficientes para oferta de educação de qualidade. De fato, uma educação de qualidade se constrói mediante investimentos na infraestrutura escolar de forma adequada, salários dignos e planos de carreira aos profissionais da educação, formação continuada, aquisição de materiais didáticos entre outros. Os dados, porém, mostram a existência de municípios trabalhando com baixos valores de recursos financeiros por aluno-ano, devido, talvez, ao seu baixo PIB per capita. No entanto, em alguns casos, o IDEB desses municípios é superior a municípios com PIB per capita elevado.

Podemos verificar isso no município de Altair, região de Barretos, pois possui um PIB per capita de $\mathrm{R} \$ 45.624,00$, com gasto de $\mathrm{R} \$ 8.161,00$ por aluno-ano e IDEB de 4,5; enquanto o município de Cajobi possui um PIB per capita de R $14.600,00$, gasto por aluno-ano de $\mathrm{R} \$ 5.925,00$ e IDEB de 7,1.

Na região Central, a discrepância é menor porque podemos observar que os municípios que gastam mais, também estão com os IDEBs maiores, dado que confirma a forte correlação entre IDEB e gasto por aluno-ano/PIB per capita para as três situações da análise: total de municípios da região; municípios com meta igual ou acima e municípios com metas abaixo do previsto. 
Destacam-se, nesta região, as cidades de Itápolis, Santa Ernestina e Cândido Rodrigues porque possuem IDEB 7,3, 7,1 e 7,0, respectivamente, com gasto médio por aluno-ano de $\mathrm{R} \$ 7.932,00$. Os PIBs per capita de Itápolis e Cândido Rodrigues se assemelham e ficam em média R\$21.699,00, mas a cidade de Santa Ernestina que possui PIB per capita de R $\$ 10.654,00$.

O município de Araraquara apresenta um IDEB que não condiz com a média dos gastos realizados, pois seu IDEB é de 5,7, gastos de $\mathrm{R} \$ 9.762,00$ e um PIB per capita de $\mathrm{R} \$ 25.642,00$.

Conhecer os gastos por aluno-ano praticados pelos municípios permite perceber se as políticas educacionais adotadas estão adequadas ao desenvolvimento da educação de qualidade e a prioridade dada à educação em termos financeiros, pois cabe ao poder público a garantia do direto à educação de qualidade. Essa garantia está fixada na Constituição Federal de 1988 e na Lei de Diretrizes e Bases da Educação Nacional, como também no Plano Nacional de Educação e no Plano de Desenvolvimento da Educação.

A gestão dos sistemas educacionais deve pautar-se pelo princípio da gestão democrática, a fim de incentivar e fortalecer os colegiados para decisões sobre a educação. A gestão financeira, nesse caso, é decisiva, conforme podemos observar, para que o padrão de qualidade seja atendido.

A meta 20 do PNE prevê a ampliação do investimento público em educação para 7\% do PIB Nacional até 2019 e 10\% até 2024; entretanto, considerando os resultados desse estudo, entendemos que aumentar a previsão de gastos por aluno-ano sem ação efetiva dos mecanismos de fiscalização, controle e a qualificação da gestão poderá aumentar ainda mais as desigualdades educacionais. Isso porque alguns municípios investem e progridem na qualidade da educação; enquanto outros, possivelmente devido à ausência ou ineficácia de planejamento e/ou gestão adequada, decrescem nos seus indicadores de qualidade.

Acreditamos que a aprovação de uma Lei de Responsabilidade Educacional, como prevista para o ano de 2016, favorecerá o desenvolvimento da educação em todas as modalidades e etapas.

Podemos interpretar que, com base nos resultados deste estudo, as políticas educacionais locais, para alguns municípios, não estão alinhadas ao PNE e PDE para o desenvolvimento das ações contidas no Plano de Ações Articuladas. 
Estudos e pesquisas na área de políticas públicas para educação e gestão educacional, que atentem para os investimentos realizados e sua relação com os indicadores de qualidade, são uma necessidade nos dias atuais.

\section{Referências}

BRASIL. Lei n. 4.320 de 17 de março de 1964. Estatui normas gerais de direito financeiro para elaboração e controle dos orçamentos e balanços da União, dos Estados, dos Municípios e do Distrito Federal. Diário Oficial da União, Poder Executivo, Brasília, DF, 23 mar. 1964.

BRASIL. Constituição (1988). Constituição da República Federativa do Brasil: promulgada em 5 de outubro de 1988. Brasília, DF: Senado, 1988.

BRASIL. Lei n. 9394, de 20 de dezembro de 1996. Estabelece as diretrizes e bases da Educação Nacional. Diário Oficial da União, Poder Executivo, Brasília, DF. 09 jan. 1997.

BRASIL. Lei n. 10.172, de 09 de janeiro de 2001. Estabelece o Plano Nacional de Educação. Diário Oficial da União, Poder Executivo, Brasília, DF, 09 jan. 2001.

BRASIL. Decreto presidencial n. 6.094, de 24 de abril de 2007. Dispõe sobre implementação do Plano de Metas Compromisso Todos pela Educação, pela União, em regime de colaboração com Municípios, Distrito Federal e Estados, Diário Oficial da União, Poder Executivo, Brasília, DF, 24 abr. 2007a.

BRASIL. Lei n. 11.494, de 20 de junho de 2007. Regulamenta o Fundo de Manutenção e Desenvolvimento da Educação Básica e de Valorização dos Profissionais da Educação - FUNDEB. Diário Oficial da União, Poder Executivo, Brasília, DF, 22 jun. 2007b.

BRASIL. Ministério da Educação. O Plano de Desenvolvimento da Educação. Razões, princípios e Programas. Brasília: MEC, 2007c.

BRASIL. Ministério da Educação. Plano de Metas Compromisso Todos pela Educação: Plano de ações articuladas - Brasília, 2008. Disponível em: <www.mec.gov.br>. Acesso em: 03 mai. 2013.

BRASIL. Ministério da Educação. Fundo Nacional do Desenvolvimento da Educação. Sistema de Informações sobre Orçamentos Públicos em Educação (SIOPE). Brasília, DF: MEC, 2009a. Disponível em: <http://www.fnde.gov.br/index.php/sistemas-siope>. Acesso em: 15 jun. 2013.

BRASIL. Ministério da Educação. Fundo Nacional do Desenvolvimento da Educação. Portaria Interministerial $\mathbf{n}^{\mathbf{0}}$ 19, de 27 de dezembro de 2013. Brasília, DF: MEC, 2009b. Disponível em: <http://www.fnde.gov.br/fnde/legislacao/portarias>. Acesso em: 15 ago. 2013. 
BRASIL. Ministério da Educação. Orientações Gerais para elaboração do Plano de Ações Articuladas (PAR) dos Municípios - versão revisada e ampliada. Brasília, 2009b. p. 1-54.

BRASIL. Conselho Nacional de Educação. Secretaria de Educação Básica. Parecer n. 008. Estabelece normas para aplicação do inciso IX do artigo $4^{\circ}$ da Lei n. 9.394/96 (LDB), que trata dos padrões mínimos de qualidade de ensino para a Educação Básica pública. 2010.

BRASIL. Tribunal de Contas do Estado de São Paulo. O Tribunal e a Gestão Financeira dos Prefeitos. 2012. Disponível em: <https://www4.tce.sp.gov.br/sites/default/files/images/manual-gestao-financeira prefeitura-municipal.pdf $>$. Acesso em: 23 jun. 2014.

BRASIL. Ministério da Educação. Fundo Nacional do Desenvolvimento da Educação. Portaria Interministerial 16. Brasília. DF, 17 dez. 2013a. Disponível em: <http://www.fnde.gov.br/fnde/legislacao/portarias/portarias-2013>. Acesso em: 15 jun. 2013.

BRASIL. Ministério da Educação. Fundo Nacional do Desenvolvimento da Educação. Portaria Interministerial 19. Brasília, DF, 27 dez. 2013b. Disponível em: <http://www.fnde.gov.br/fnde/legislacao/portarias/portarias-2013>. Acesso em: 15 jun. 2013.

BRASIL. Lei n.13.005, de 25 de junho de 2014. Plano Nacional de Educação. Diário Oficial da União, Poder Executivo, Brasília, DF, 25 jun. 2014.

CALLEGARI, C. FUNDEB financiamento da educação pública no Estado de São Paulo. São Paulo, APEOESP, 2009.

DOURADO, L. F. (Coord.), OLIVEIRA, J.F.; SANTOS, C.A. A qualidade da educação nacional. educação: conceitos e definiçõos. Série Documental: Textos para Discussão. Brasília, DF, v. 24, n. 22, 65p., 2007.

INSTITUTO NACIONAL DE ESTUDOS E PESQUISAS. Dados e informações Educacionais. 2007. Disponível em: < www.IDEB.INEP.gov.br>. Acesso em: 24 ago. 2014.

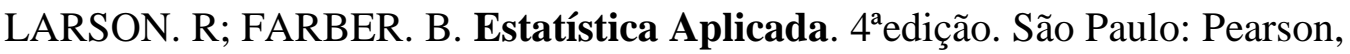
2010 .

LEMES. S. S. Uma breve discussão sobre fundamentos de avaliação e indicadores educacionais para se melhor compreender a avaliação e gestão do currículo. Unesp/UNIVESP. $1 \mathrm{a}$ edição. 2013.2 Disponível em: <http://www.acervodigital.unesp.br/handle/123456789/65513> acesso em: 26 dez.2014.

LEMES. S. S. O currículo para a escola democratiza: das pistas históricas às perspectivas necessárias. Unesp/UNIVESP. 1a edição. 2013. Disponível em: <http://www.acervodigital.unesp.br/handle/123456789/65513> acesso em: 26 dez.2014. 
MELO, G. M. B. P. Planejamento da Política Educacional no Brasil: da diversidade conceitual e programática a uma proposta técnica de alinhamento estratégico. Dissertação (Mestrado) - Universidade de Brasília, Brasília, 2013.

OLIVEIRA. D; DOURADO. L.F; et al. Por um Plano Nacional de Educação (20112020) como política de Estado. Rev. Bras. Educ. vol.16, n.47. Rio de Janeiro, mai./ago. 2011.

\section{Como referenciar este artigo}

OLIVEIRA, Rejane. LEMES, Sebastião de Souza. Relação IDEB e gasto aluno-ano: algumas aproximações de correlações e sua pertinência para melhoria dos investimentos em educação. Revista on line de Política e Gestão Educacional, Araraquara, v.20, n.3, p. 367-384, 2016. Disponível em: <http://dx.doi.org/10.22633/rpge.v20.n3.9743>. ISSN: $1519-9029$.

Submetido em: junho/2016

Aprovado em: novembro/2016 